\title{
Resistance to respiratory depression in 'opioid induced hyper-algesia': a hidden clinical danger
}

\section{Correspondence to}

Dr Marie Joseph, St Raphael's

Hospice, Sutton SM3 9DX, UK

mariejoseph@straphaels.org.uk

Received 4 October 2018

Revised 15 November 2018

Accepted 19 December 2018

Published Online First

12 January 2019

\section{(D) Check for updates}

(c) Author(s) (or their employer(s)) 2019. No

commercial re-use. See rights

and permissions. Published by BMJ.

To cite: Joseph M. BMJ

Supportive \& Palliative Care 2019;9:280.

\section{Marie Joseph}

\section{EXPRESSION OF CONCERN}

This paper has been withdrawn for data protection reasons. 